\title{
Unilateral Mandibular Space Regaining with Modified Lingual Arch and Ni-Ti Open-coil Spring: A Case Report
}

\author{
Bindu Kadian ${ }^{1}$, Natasha Saini ${ }^{2}$, Ritu Namdev ${ }^{3}$
}

\begin{abstract}
Premature extraction or exfoliation of deciduous tooth results in space loss which causes malocclusion. Interception of space loss by using space regainer aids in prevention of malocclusion. This article highlights the use of modified lingual arch and nickel-titanium (Ni-Ti) open-coil spring in unilateral space regaining of mandibular arch. The $\mathrm{Ni}-\mathrm{Ti}$ open-coil spring along with cross-arch stabilization is the mechanics used in this study for space gaining.

Keywords: Modified lingual arch, Ni-Ti open-coil spring, Space gain.

Journal of South Asian Association of Pediatric Dentistry (2020): 10.5005/jp-journals-10077-3037
\end{abstract}

\section{INTRODUCTION}

Premature extraction or exfoliation of deciduous tooth or teeth often results in space loss. As a result of space loss, the unerupted permanent tooth may erupt buccally or lingually or may remain impacted. Early exfoliation of primary second molar results in more space loss than primary first molar. ${ }^{1}$ Ronnermann and Thilander evaluated unilateral space loss after extraction of the mandibular primary molars and compared it with the contralateral quadrant. They found that the space loss associated with mandibular deciduous first molar are 0.8-1.7 mm; mandibular deciduous second

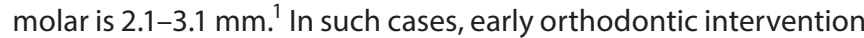
using space regainer is required, which helps to promote favorable developmental changes. ${ }^{2}$

Various appliances are designed to regain the space such as sling shot space regainer, Hotz lingual arch, Gerber space regainer, King's appliance, etc. Space regainer aids in the interception of malocclusion by eliminating the potential of developing irregularities in developing dentition.

If space regaining is planned, a comprehensive analysis is utmost important prior to any treatment decisions. The factors that should be considered in the analysis include age at the time of tooth loss, dentofacial development, tooth that has been lost, space available, and space needed. ${ }^{3}$ Then the regained space must be maintained.

The treatment should be such that no further disharmonies develop. Hence, the following is a case of judicious use of "lingual arch with $\mathrm{Ni}-\mathrm{Ti}$ open-coil spring technique" in regaining the space lost due to the untimely loss of primary second molar.

\section{Case Description}

A 10-year-old male patient reported with a chief complaint of decayed left lower back (36) tooth. Past medical history was insignificant. Past dental history revealed that the patient had undergone extraction of left lower primary second molar (75) due to dental caries 3 years ago. On clinical examination, mesial migration of the adjacent permanent first molar (36) into the premolar space was apparent. The mandibular arch had permanent incisors and both first molars, primary left canine and first molar, and erupting right first premolar (Fig. 1). Radiographic
${ }^{1-3}$ Department of Pedodontics and Preventive Dentistry, Postgraduate Institute of Dental Sciences, Rohtak, Haryana, India

Corresponding Author: Bindu Kadian, Department of Pedodontics and Preventive Dentistry, Postgraduate Institute of Dental Sciences, Rohtak, Haryana, India, Phone: +91 9466349024, e-mail: Bindu.18july@ gmail.com

How to cite this article: Kadian B, Saini N, Namdev R. Unilateral Mandibular Space Regaining with Modified Lingual Arch and $\mathrm{Ni}-\mathrm{Ti}$ Open-coil Spring: A Case Report. J South Asian Assoc Pediatr Dent 2020;3(1):27-29.

Source of support: Nil

Conflict of interest: None

examination revealed mesial tipping of 36 , thereby causing complete space loss for premolar (35) (Fig. 2). Moyer's analysis showed $6.2 \mathrm{~mm}$ of space deficiency. After endodontic treatment

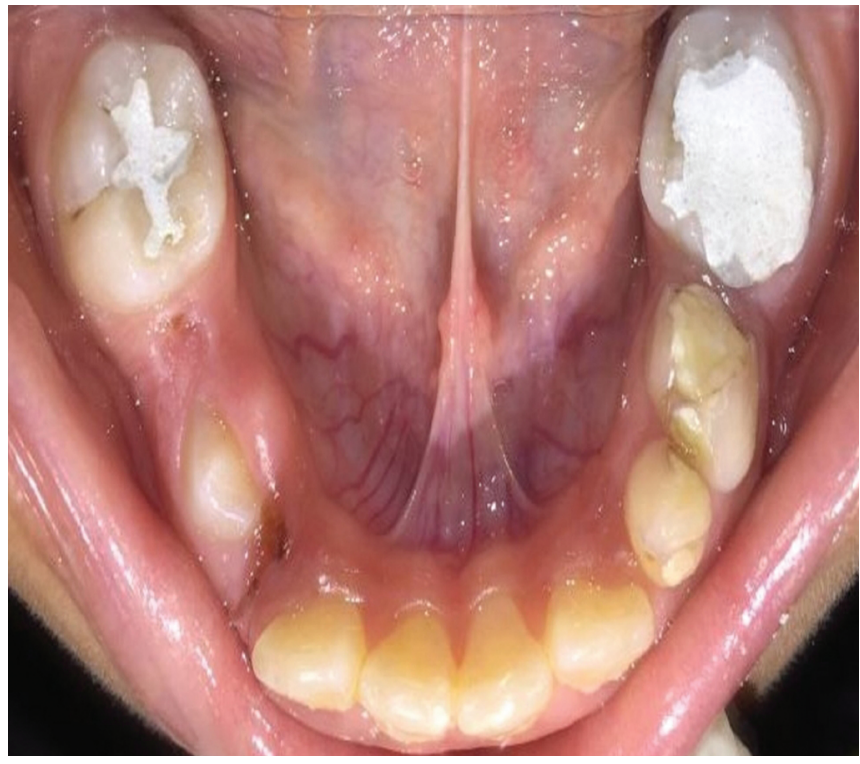

Fig. 1: Mandibular pretreatment occlusal view

() The Author(s). 2020 Open Access This article is distributed under the terms of the Creative Commons Attribution 4.0 International License (https://creativecommons. org/licenses/by-nc/4.0/), which permits unrestricted use, distribution, and non-commercial reproduction in any medium, provided you give appropriate credit to the original author(s) and the source, provide a link to the Creative Commons license, and indicate if changes were made. The Creative Commons Public Domain Dedication waiver (http://creativecommons.org/publicdomain/zero/1.0/) applies to the data made available in this article, unless otherwise stated. 


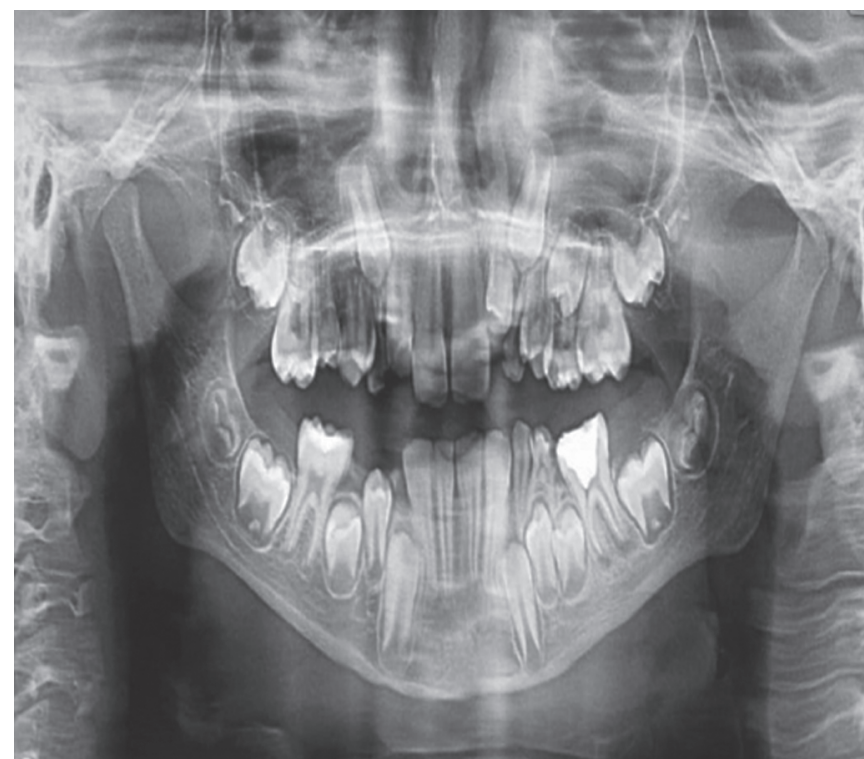

Fig. 2: Preoperative orthopantomograph

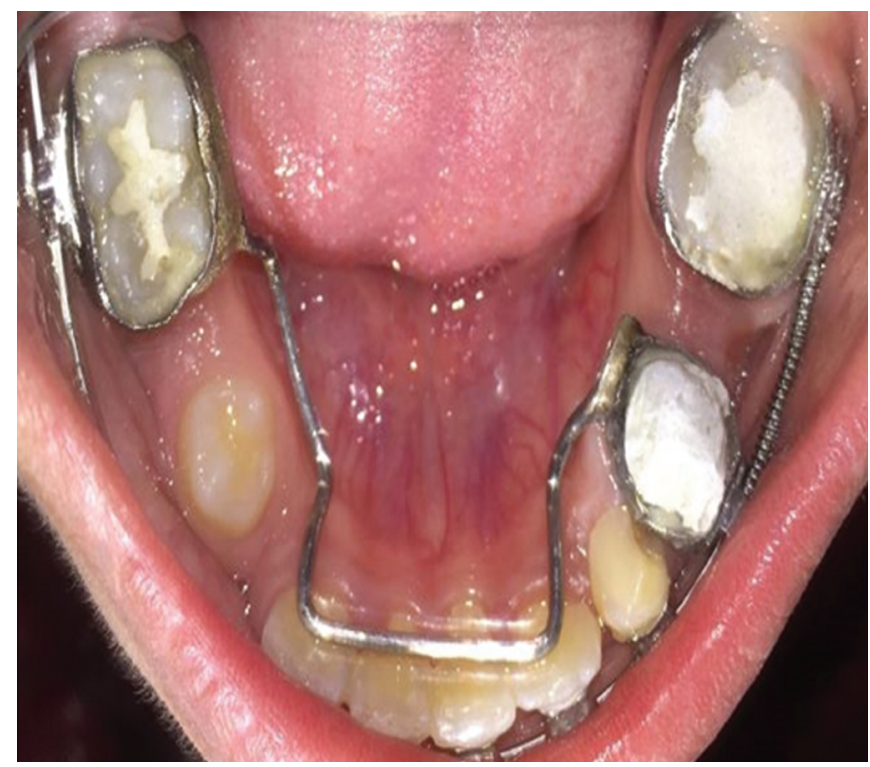

Fig. 4: After regaining space

of 36 , it was decided to regain the space for 35 by using space regainer. The permanent right first molar (46) and primary left first molar (74) were banded $(0.005 \times 0.180$ inch) with molar tubes ( $0.7 \mathrm{~mm}$ diameter, $10 \mathrm{~mm}$ length) and welded to it buccally. To prevent mesial migration of primary left first molar and for crossarch stabilization, a fixed lingual arch with bands $(0.005 \times 0.180$ inch) fitted on the first deciduous molar (74) of the treatment side and the first permanent molar (46) on the opposite side was constructed and cemented. The permanent left first molar (36) was banded $(0.005 \times 0.180$ inch) with molar tubes $(0.7 \mathrm{~mm}$ diameter, $10 \mathrm{~mm}$ length) welded to it buccally. All the permanent incisors and primary canine were bonded with the edgewise bracket. The $\mathrm{Ni}-\mathrm{Ti}$ open-coil spring was cut $2 \mathrm{~mm}$ more than the distance between 36 and 74 molar tubes and placed between them by incorporating into the $0.014 \mathrm{Ni}-\mathrm{Ti}$ mandibular archwire

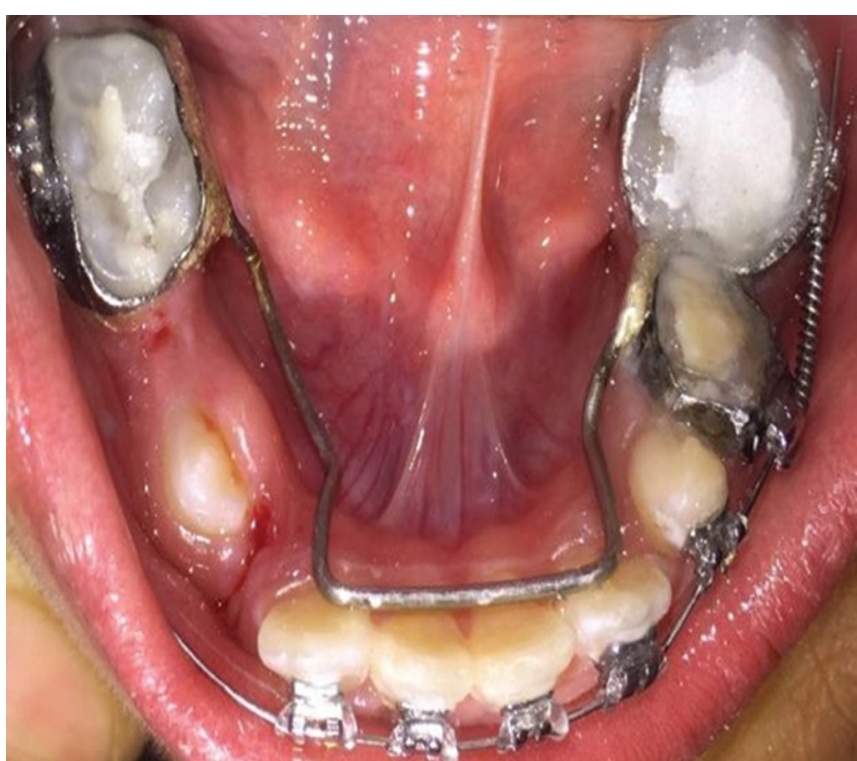

Fig. 3: Modified lingual arch and $\mathrm{Ni}-\mathrm{Ti}$ open coil spring engaged in archwire

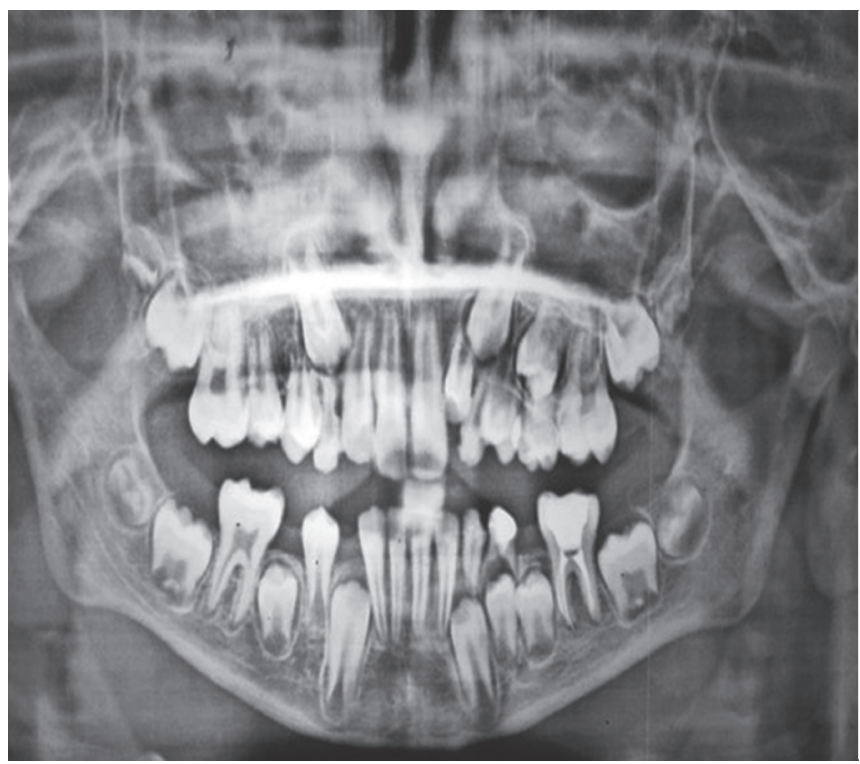

Fig. 5: Postoperative orthopantomograph

(Fig. 3). After 2 weeks, the space was slightly regained and then $0.016 \mathrm{Ni}-\mathrm{Ti}$ round wire was inserted with $2 \mathrm{~mm}$ of excess coil spring. Again, after 2 weeks, the wire was changed to a $0.018 \mathrm{Ni}-\mathrm{Ti}$ and finally to a $0.019 \times 0.025 \mathrm{Ni}$-Ti wire. After 2 months, $5.9 \mathrm{~mm}$ of space was gained (Fig. 4). Orthopantomogram of the patient demonstrated near-complete uprighting of the mandibular left first molar (Fig. 5). Then after regaining the space, complete assembly was replaced by fixed lingual arch space maintainer (Fig. 6) for maintaining the regained space. Space lost due to mesial tipping of permanent molar was corrected and the patient is under observation until the eruption of premolars and canine. Disking of permanent teeth or distalization of the permanent firstleft molar may be considered after the eruption of the permanent left canine, if the space available for eruption of the left second premolar is deficient. 


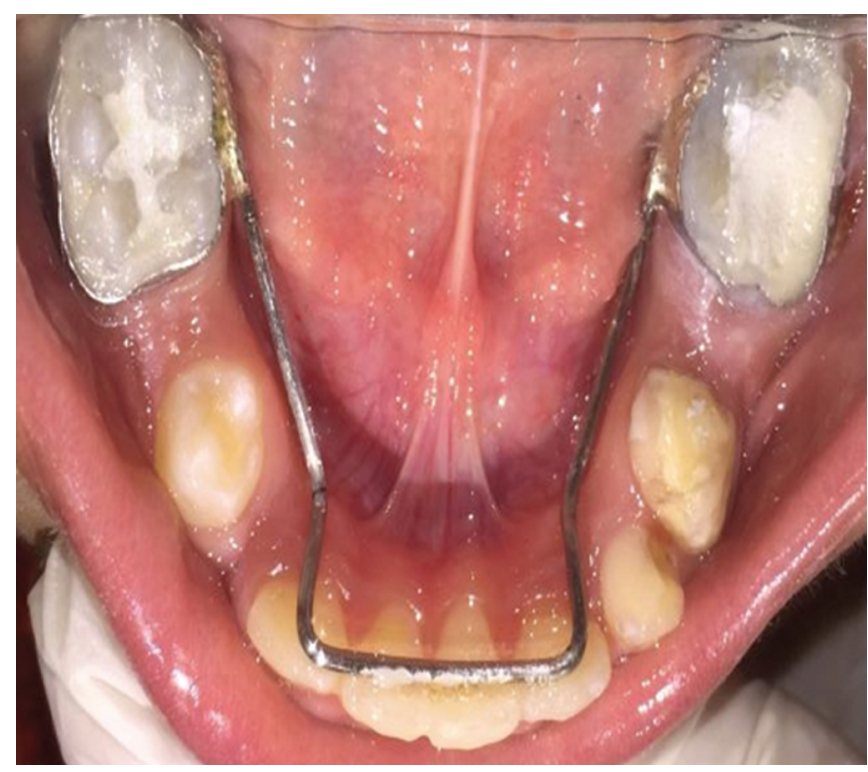

Fig. 6: Mandibular posttreatment occlusal view

\section{Discussion}

Most common causes of space loss within an arch is primary teeth with interproximal caries followed by loss of primary molars without proper space management. ${ }^{4}$ The degree of space loss varies according to the arch, site in the arch, and time elapsed since tooth loss. ${ }^{5}$ Therefore, loss of space in the dental arch that interferes with the desired eruption of the permanent teeth may require evaluation and early intervention.

Although various treatment options are available for the management of space loss, they were not used in the current case, as the complete space loss design framework of Gerber, jack screw, band, and U loop cannot be fabricated. Also, target tooth movement of 36 was required which could not be achieved by space regainers such as sliding loop, double-banded space regainer, and Hotz lingual arch.

In the present case, there was a need for the distal tipping and uprighting of permanent molar to regain the space for the eruption of the second premolar along with prevention of movement of the primary first molar of treatment side. So to achieve the desirable results, modified lingual arch with segmental orthodontics using $\mathrm{Ni}$-Ti open-coil spring was used. There is negligible risk of anchorage loss while using the "lingual arch crossbow," as the entire lingual arch takes the role of anchorage, distributing force over a large number of teeth. ${ }^{6}$ The $\mathrm{Ni}-\mathrm{Ti}$ coils have a long range of the superelastic activity with minimal load fluctuation in spite of the large deflection due to excellent spring back and superelasticity. ${ }^{7}$ This property enables to achieve a wide range of tooth movement. The use of light $\mathrm{Ni}-\mathrm{Ti}$ archwire allows easy placement of spring for space regaining. The advantage of this novel method over conventional space regaining methods is that it allows movement of target tooth only without any undesirable effects on other teeth such as migration, tipping, and root resorption. As it is a fixed appliance, patient compliance was good but required good maintenance of oral hygiene.

King's in 1977 first described an appliance for regaining of space by using lingual arch as anchorage unit and a straight section of wire with an open-coil spring for regaining the space. ${ }^{8}$ After it, the use of lingual arch as anchorage and $\mathrm{Ni}-\mathrm{Ti}$ coil spring and archwire became popular in various modified ways. Negi ${ }^{9}$ used the shape memory property of 0.016 inch $\mathrm{Ni}-\mathrm{Ti}$ wire for regaining the space by distalizing and uprighting the first molar. Chalakka et al. ${ }^{6}$ introduced lingual arch crossbow and double-banded space regainers for regaining the lost space. Also, in the current case lingual arch, edgewise brackets with $\mathrm{Ni}-\mathrm{Ti}$ archwire, and coil spring were used which not only enhanced the anchorage but also resulted in the movement of specific tooth. Additionally, the space regainer's design used in this case can be easily and effectively used in situations with complete space loss due to mesial tipping of permanent molar.

\section{CONCLUSION}

The goal of space regaining intervention is to recover the lost arch width and perimeter and improve the eruptive position of succedaneous teeth. The technique used here fulfilled the goal by permitting the movement of only offending tooth and stabilization of the remaining arch, where conventional space regainers cannot be used.

\section{References}

1. Ronnerman A, Thilander B. The effect of early loss of primary molars on tooth eruption and space conditions: a longitudinal study. Acta Odontol Scand 1977;35(5):229-239. DOI: 10.3109/00016357709019797.

2. Proffit W. Contemporary Orthodontics. 2nd ed., Mosby Year Book, pp. 380-383.

3. Kanellis MJ. Orthodontic treatment in the primary dentition. In: Bishara SE. Textbook of Orthodontics. Philadelphia, Pa: WB Saunders Co; 2001. pp. 248-256.

4. Bell RA, Dean JA, McDonald RE, et al. Management of the developing occlusion. In: Dean JA, Avery DR, McDonald RE. McDonald and Avery's Dentistry for the Child and Adolescent. 9th ed., Maryland Heights, Mo.: Mosby Elsevier; 2011. pp. 550-613.

5. Finucane D. Rationale for restoration of carious primary teeth: a review. Eur Arch of Pediatr Dent 2012;13(6):281-292. DOI: 10.1007/ bf03320828.

6. Chalakka P, Thomas AM, Akkara F, et al. New design space regainers: 'Lingual arch crossbow' and 'Double banded space regainer'. J Indian Soc Pedod Prev Dent 2012;30(2):161-165. DOI: 10.4103/09704388.100001.

7. Miura F, Mogi M, Ohura Y, et al. The super-elastic Japanese NiTi alloy wire for use in orthodontics. Part III studies on the Japanese NiTi alloy coil springs. Am J Orthod Dentofacial Orthop 1988;94(2):89-96. DOI: 10.1016/0889-5406(88)90356-3.

8. Kisling $\mathrm{E}$, Hoff ding J. Premature loss of primary teeth: Part 111, drifting patterns for diff erent types of teeth aft er loss of adjoining teeth. $J$ Dent Child 1979;46:34-38.

9. Negi KS. NiTi bonded space regainer/maintainer. J Indian Soc Pedod Prev Dent 2010;28(2):113-115. DOI: 10.4103/0970-4388.66751. 